\title{
WEATHERED BIOTITE FROM MATSUSAKA, CENTRAL JAPAN
}

\author{
YoshIRo TSUZUKI and KeINOSUKE NAGASAWA \\ Department of Earth Sciences, Faculty of Science, \\ Nagoya University, Chikusa, Nagoya \\ and \\ KATSU ISOBE \\ Mie-ken Science Education Center, Yokkaichi
}

\begin{abstract}
Three kinds of elongated crystals of weathered biotite were found in a terrace deposit at Matsusaka, Mie Prefecture. They are mainly composed of Al-vermiculite, kaolinite, and gibbsite. The texture and orientational relationship of these alteration products were studied with conclusions that much material, especially $\mathrm{Al}_{2} \mathrm{O}_{3}$, should have been supplied from the environment, and that the degree of preferred orientation of each alteration mineral with respect to the original biotite depends on the amounts of materials introduced to it.
\end{abstract}

\section{Introduction}

The alteration of biotite is of great importance to the study of the weathering process for the following two reasons. Firstly, biotite is readily altered to various minerals: chlorite, vermiculite, kaolinite, gibbsite, etc., and therefore its alteration may be useful as an indicator of the degree and condition of weathering. Walker (1948), Jackson (1952, 1963), Fieldes and Swindale (1954), Kato (1963, 1965), Wilson (1966) and others have made investigations along this line. Secondly, these alteration products, all being of layer structure, usually develop with a definite orientational relationship to the original biotite, and therefore this relationship may supply us with information on the 
mechanism of the alteration. Recent paper by Wilson (1966) is an important contribution also to this field.

Weathered biotite crystals elongated in the direction normal to the cleavage were found at Matsusaka, Mie Prefecture, and the outline of their occurrence and properties was given by one of the present writers (Isobe, 1966). The writers carried out mineralogical investigations of this weathered biotite by means of $\mathrm{X}$-ray powder and single-crystal diffraction, optical examination, differential thermal analysis, chemical analysis, apparent specific gravity measurement, etc. The results are given in this paper, together with discussion on the mechanism of its alteration.

\section{Occurrence}

The weathered biotite crystais were found abundantly in a gravel bed of the Pleistocene age in the southern part of the town of Matsusaka. The geology of this district was studied by Kimura and Takehara (1965). They classified the river terraces into three groups: low-level, middle-level, and high-level, and showed that the gravel bed in question belongs to the high-level terrace gravel. The gravel is inferred to be supplied mainly from the hills to the south where granite and gneiss of the Ryoke metamorphic complex are exposed.

A sketch of the outcrop where the specimens were collected is shown in Fig. 2. The gravel is composed of cobbles of granite, gneiss, diorite, chert, etc. The gravel bed is divided into two parts by the intermittent intercalation of silt. The upper gravel consists of less weathered cobbles and a sandy matrix, in which black spots of amorphous manganese compounds are disseminated. Its upper part has changed colour into brownish red. The lower gravel consists of more weathered cobbles and a clayey matrix. The present earth surface shown in Fig. 2 is not the original terrace surface; brownish red soil of about $100 \mathrm{~cm}$ thick and brownish red gravel of about 


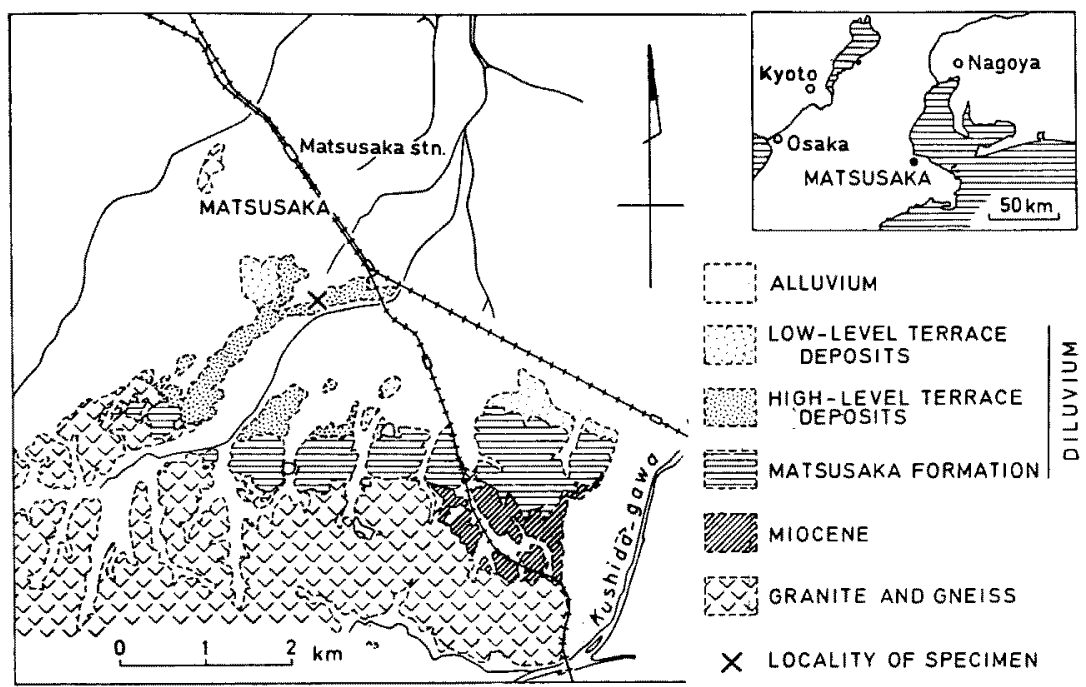

Fig. 1. Map of the Matsusaka area showing the locality of specimens and its geological setting. Geology after Kimura and Takehara (1965).

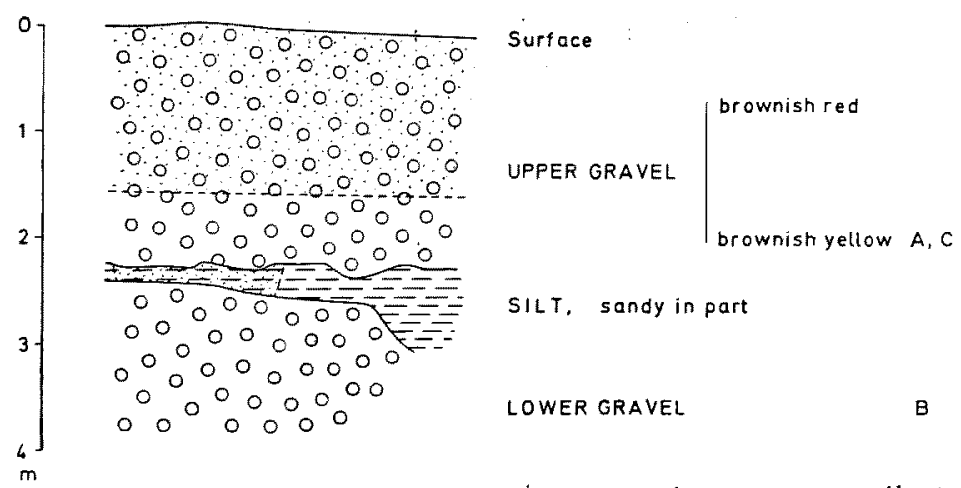

Fig. 2. Sketch of the outcrop where the specimens were collected.

$30 \mathrm{~cm}$ thick have been lost by cultivation.

The clay fractions of the matrix of gravel and the silt were examined by X-ray diffraction. X-ray diffraction diagrams were recorded for oriented aggregates prepared from untreated and chemically treated clay fractions. Fig. 3 shows the diagrams for untreated clay fractions. The clay fraction of the upper part of the brownish 


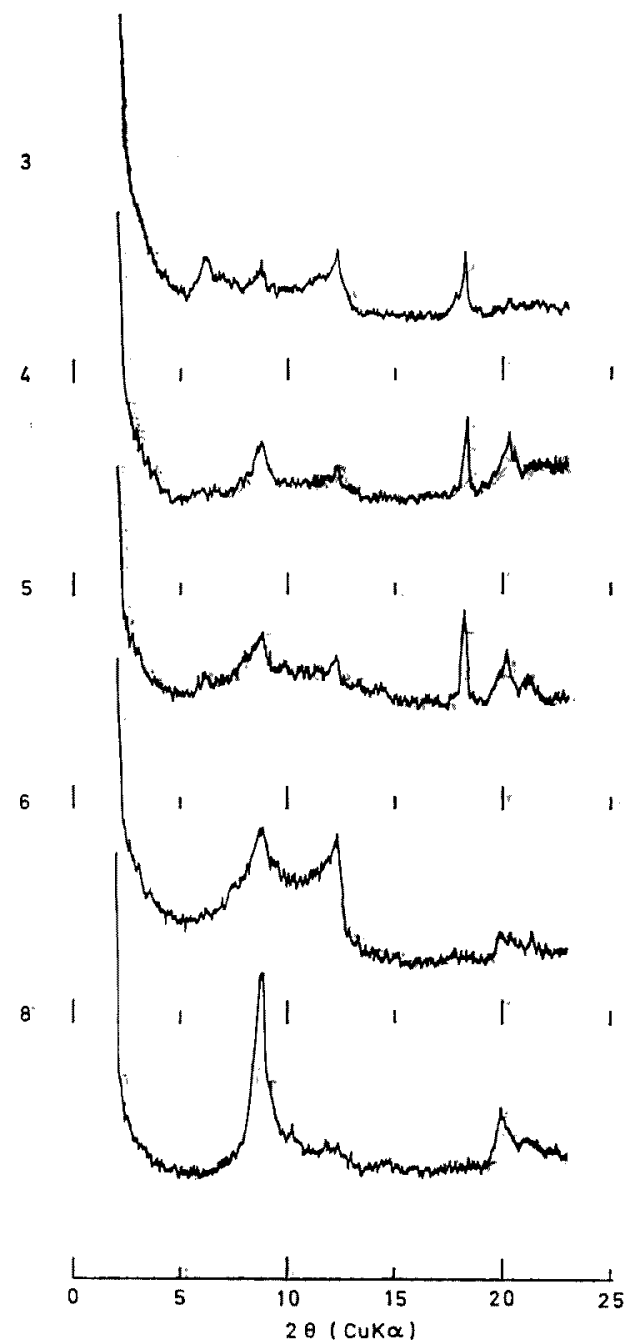

Fig. 3. X-ray diffractometer records for oriented aggregates of clay fractions of gravel and silt at the locality of the specimens. 3 , upper part of the brownish red upper gravel; 4, lower part of the brownish red upper gravel; 5 , brownish yellow upper gravet; 6 , silt ; 8 , lower gravel. 
red gravel is composed of vermiculite, illite, and metahalloysite. This vermiculite collapses in part on $\mathrm{NH}_{4} \mathrm{NO}_{3}$ treatment (Walker, 1949), and a dual peak with maxima at $14 \AA$ and $12 \AA$ is produced. The clay fraction of the remaining part of the upper gravel and of the silt is mainly composed of halloysite and metahalloysite, and that of the lower gravel exclusively of halloysite. In the diagrams for the upper gravel, a sharp gibbsite reflection occurs at about $4.9 \AA$.

Three kinds of weathered biotite specimens $A, B$ and $C$, were examined in this study. Specimen $A$ was collected from the sandy matrix of the upper gravel, of which the lower part is abundant in it. Specimen B was collected from weathered cobbles of granite in the lower gravel bed. Specimen $C$ was collected from weathered cobbles of granite in the upper gravel bed, but is of rather rare occurrence.

\section{General mineralogy}

Macroscopic appearance

Specimen A is of grayish white colour, but its surface is stained dark gray. It is elongated in the direction normal to the cleavage attaining to the length of $10-20 \mathrm{~mm}$ in this direction, and is usually curved resulting in a vermicular shape (Fig. 4). Specimen B is of reddish brown colour and is not so long as specimen $A$ (Fig. 5). Specimen $C$ has an appearance similar to specimen $A$.

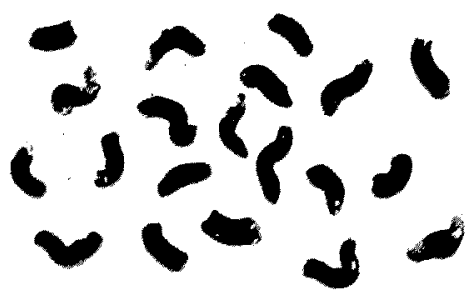

Fig. 4. Specimen A. $\times 0.5$

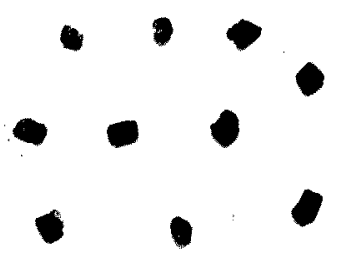

Fig. 5. Specimen B. $\times 0.5$ 
In order to ascertain whether the specimens become elongated as the progress of weathering, the ratio of the height normal to the cleavage to the diameter in the cleavage was measured. The result is shown in Table 1, together with the result for biotite from less weathered granite and fresh gneissose granodiorite near Matsusaka. These results indicate that specimen $\mathrm{A}$ has been elongated to about three times the height of fresh biotite, and that specimen $B$ has been elongated about 1.5 times.

Table 1. Ratios of the height normal to the cleavage to the diameter in the cleavage for the weathered biotite specimens and some fresh biotites.

\begin{tabular}{l|l}
\hline Specimen A & 2.83 \\
Specimen B & 1.19 \\
Specimen C & 2.29 \\
Biotite in weakly weathered granitc near Matsusaka & 0.99 \\
Biotite in fresh gneissose granodiorite near Matsusaka & 0.75 \\
\hline
\end{tabular}

X-ray powder data

$\mathrm{X}$-ray diffractometer records for powder specimens are shown in Fig. 6.

Specimen $\mathrm{A}$ is composed mainly of kaolinite and gibbsite accompanied by hydrobiotite and a small amount of Al-vermiculite. The kaolinite is of $b$-axis disordered type judging from the prism and pyramidal reflections. The hydrobiotite gives a broad basal reflection at $10.4 \AA$. This peak becomes more diffuse and a shoulder is produced at $11.6 \AA$ by boiling in magnesium acetate solution (Rolfe \& Jeffries, 1952). The amounts of the constituent minerals were roughly estimated by relative intensities of diffraction peaks of these minerals as shown in Table 2.

Specimen $\mathrm{B}$ is composed of trioctahedral Al-vermiculite and small amounts of kaolinite and gibbsite. The identification of trioctahedral Al-vermiculite was based on the following experimental results. The 

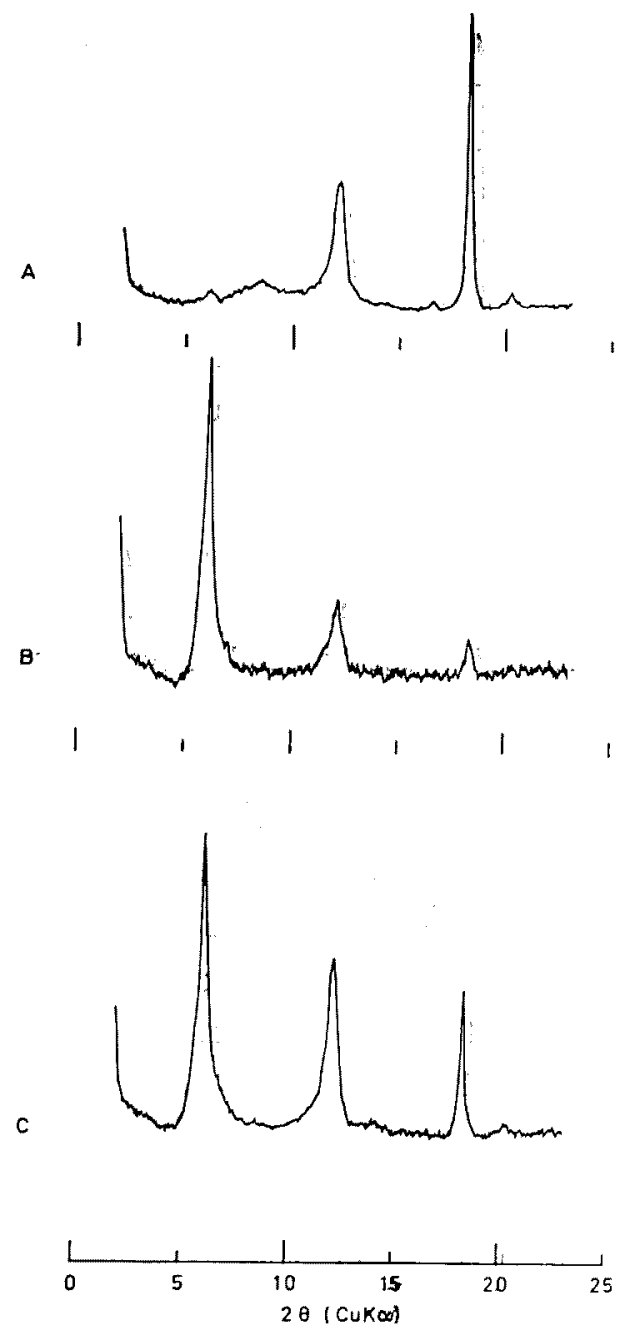

Fig. 6. X-ray diffractometer records for oriented aggregates of pulverized specimens of the weathered biotite.

basal reflection appears at $14.6 \AA$. This spacing remains unchanged on $\mathrm{NH}_{4} \mathrm{NO}_{3}$ treatment (Walker, 1949), but decreases to $11-12.5 \AA$ on $\mathrm{NH}_{4} \mathrm{NO}_{3}$ treatment after boiling in sodium citrate solution (Tamura, 1958). The 060 reflection appears at $1.537 \AA$. 
Weathered Biotite from Matsusaka, Central Japan

Table 2. Weight percentages of constituent minerals of specimen $A$ determined by various methods.

\begin{tabular}{l|c|c|c}
\hline & Hydrobiotite & Kaolinite & Gibbsite \\
\hline Chemical analysis & 9 & 42 & 49 \\
X-ray diffraction & 10 & 50 & 40 \\
Microscopic examination & 14 & 50 & 36 \\
\hline
\end{tabular}

Specimen $C$ consists of the same minerals as specimen $B$, but the amounts of kaolinite and gibbsite are much larger.

Differential thermal curves

Differential thermal curves for specimen A and B are shown in Fig. 7. The curve for specimen $A$ shows characteristic peaks of gibbsite and kaolinite. Because the endothermic peak of gibbsite at about $320^{\circ} \mathrm{C}$ is not accompanied by a subsidiary small peak, the endothermic peak at about $530^{\circ} \mathrm{C}$ is attributed only to kaolinite (Mackenzie, 1957). The slope ratio of this endothermic peak (Bramao et al., 1952) was determined as 1.50 , the value which falls in the kaolinite range. The ratio of gibbsite content to kaolinite content was estimated at 1.28 based on the area of the endothermic peaks at $320^{\circ} \mathrm{C}$ and $530^{\circ} \mathrm{C}$ (Cole \& Hosking, 1957). It is conformable to the results by other methods shown in Table 2.

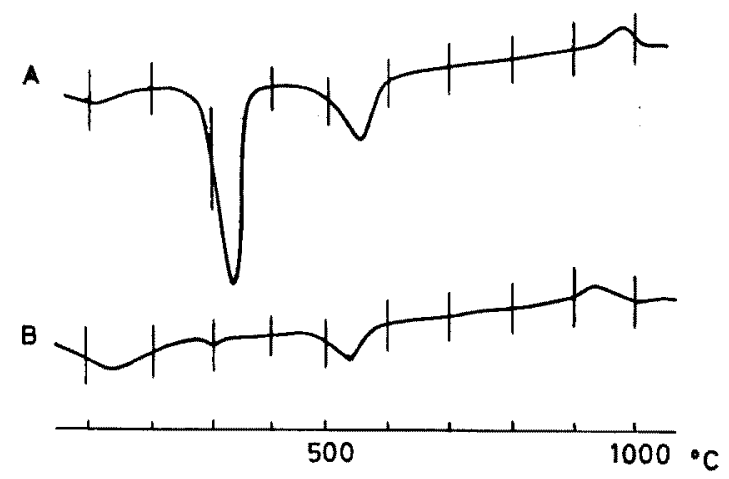

Fig. 7. Differential thermal curves for specimen A and B. 
Chemical composition

The chemical composition of specimen $A$ is shown in Table 3. The mineral composition was calculated from the chemical composition through the following procedure. The whole $\mathrm{K}_{2} \mathrm{O}$ was used to construct hydrobiotite, $\mathrm{K}_{0.5}\left(\mathrm{H}_{3} \mathrm{O}\right)_{0.5}\left(\mathrm{Mg}_{1.5} \mathrm{Fe}_{1.5}\right)\left(\mathrm{AlSi}_{3}\right) \mathrm{O}_{10}(\mathrm{OH})_{2}$. The extra $\mathrm{SiO}_{2}$ after being allotted to hydrobiotite was used to construct kaolinite, $\mathrm{Al}_{2} \mathrm{Si}_{2} \mathrm{O}_{5}(\mathrm{OH})_{4}$, together with $\mathrm{Al}_{2} \mathrm{O}_{3}$. The extra $\mathrm{Al}_{2} \mathrm{O}_{3}$ after being allotted to hydrobiotite and kaolinite was used to construct gibbsite, $\mathrm{Al}(\mathrm{OH})_{3}$. The result is shown in Table 2 .

Table 3. Chemical composition of specimen A.

\begin{tabular}{l|c}
\hline $\mathrm{SiO}_{2}$ & $24.07 \%$ \\
$\mathrm{TiO}_{2}$ & 0.04 \\
$\mathrm{Al}_{2} \mathrm{O}_{3}$ & 46.68 \\
$\mathrm{Fe}_{2} \mathrm{O}_{3}$ & 3.29 \\
$\mathrm{FeO}$ & 0.14 \\
$\mathrm{NiO}$ & 0.00 \\
$\mathrm{MgO}$ & 0.22 \\
$\mathrm{CaO}$ & 0.26 \\
$\mathrm{MnO}$ & 2.46 \\
$\mathrm{Na} 2 \mathrm{O}$ & 0.38 \\
$\mathrm{~K}_{2} \mathrm{O}$ & 0.57 \\
$\mathrm{P}_{2} \mathrm{O}_{5}$ & $0.37_{5}$ \\
$\mathrm{H}_{2} \mathrm{O}(+)$ & 20.11 \\
$\mathrm{H}_{2} \mathrm{O}(-)$ & 3.58 \\
\hline Total & $102.17_{5}$ \\
\hline
\end{tabular}

Specific gravity

The apparent specific gravity was measured, and the result is shown in Table 4 together with the specific gravity of the constituent minerals given by Deer et al. (1962). This result indicates that the specimens have only small pore space in them, a fact which is confirmed by microscopic examination. 
Table 4. Specific gravities.

\begin{tabular}{l|c}
\hline \multicolumn{2}{c}{ Apparent specific gravity for } \\
\hline Specimen A & 2.26 \\
Specimen B & 2.17 \\
Specimen C & 2.16 \\
\hline Specific gravity for constituent minerals \\
\hline Gibbsite & $\cong 2.40$ \\
Kaolinite & $2.61-2.68$ \\
Vermiculite & $\cong 2.3$ \\
Biotite & $2.7-3.3$ \\
\hline
\end{tabular}

Texture and orientational relationship

\section{Microscopic examination}

The weathered biotite crystals were examined microscopically in thin sections parallel and normal to the cleavage plane of the original biotite.

Specimen A. A photomicrograph of the section normal to the cleavage is shown in Fig. $8 \mathrm{~A}$, in which the layered aggregation of the alteration minerals is seen clearly. The three constituent minerals were distinguishable from each other by the following optical properties :

\begin{tabular}{lllc} 
& \multicolumn{1}{c}{ Colour } & Birefringence & Elongation \\
Hydrobiotite & brown & large & + \\
Kaolinite & colourless & small & + \\
Gibbsite & colourless & intermediate & -
\end{tabular}

Hydrobiotite usually forms thin layers of about $0.005 \mathrm{~mm}$ thick. Kaolinite and gibbsite form thin monomineralic layers of about $0.01-$ $0.03 \mathrm{~mm}$ thick in some parts and form intimate mixtures of both minerals of about $0.002 \mathrm{~mm}$ in diameter in the ather parts. The percentages of the constituent minerals were determined under the microscope as shown in Table 2 . The relative amounts of the minerals, 


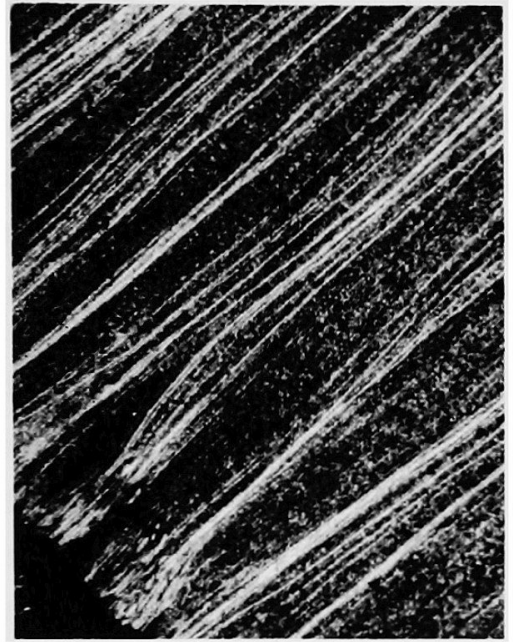

A

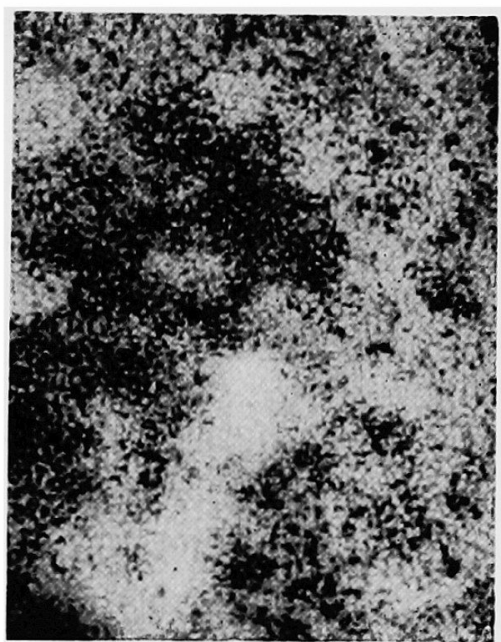

B

Fig. 8. Photomicrographs of specimen A. A, thin section normal to the cleavage, crossed nicols, $\times 54$. $B$, thin section parallel to the cleavage, one nicol, $\times 108$.

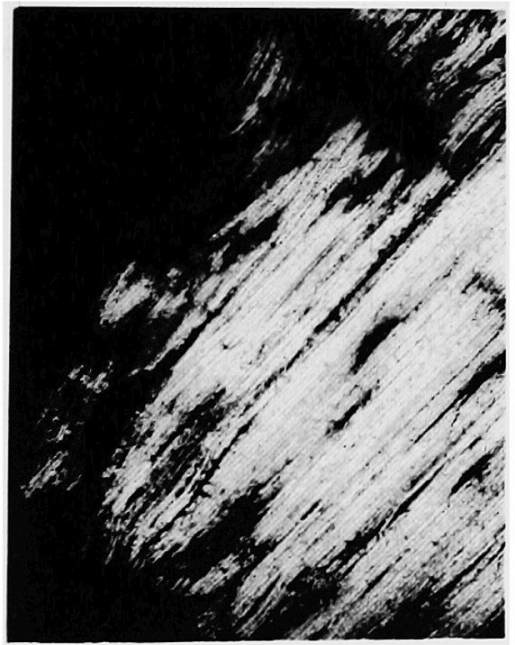

A

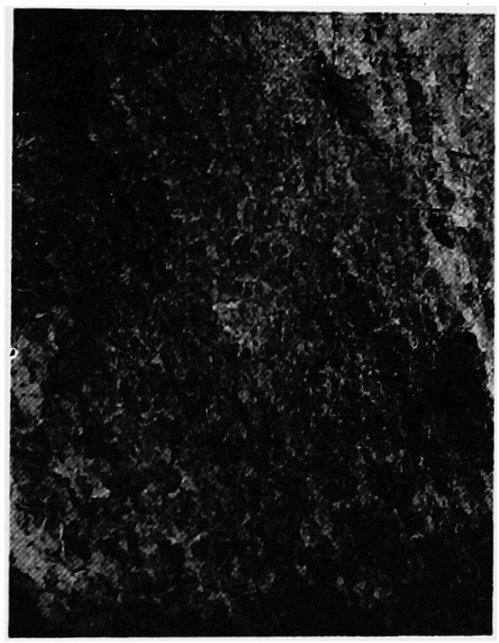

B

Fig. 9. Photomicrographs of specimen B. A, thin section normal to the cleavage, crossed nicols, $\times 54$. $B$, thin section parallel to the cleavage, one nicol, $\times 108$. 
however, vary even within a single crystal of the original biotite.

A photomicrograph of the section parallel to the cleavage is shown in Fig. 8B. Under the conoscope, the isogyre is observed in some parts, while it is hardly observable in the other parts of the same flake. Optic axial angle and the orientation of the optic axes are the same throughout the flake. The value of optic axial angle, (-) $20^{\circ}-25^{\circ}$, accords with that of hydrobiotite.

Specimen B. Photomicrographs of specimen B are shown in Fig. 9. This specimen is composed mainly of vermiculite layers with minor intercalations of kaolinite lenses. The surface of the flake has a polygonal pattern which is probably formed by edges of layers. The conoscopic figure is observable, though indistinct, in some parts, while no isogyre is observed in the other parts of the same flake. Optic axial angle is about (-) $12^{\circ}$, which may be attributed to vermiculite. The orientation of the optic axes is the same throughout the flake.

Specimen $C$. This resembles specimen B, but it is more abundant in kaolinite lenses and gibbsite lenses, and layers of intimate mixtures of both minerals are also observed.

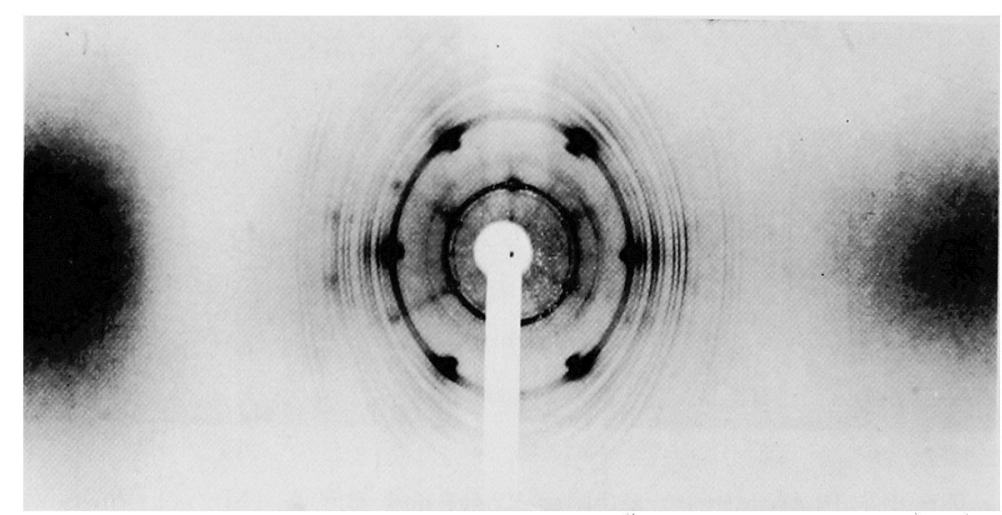

Fig. 10. Oscillation photograph of specimen A rotated around the $b$-(or pseudo $b$-) axis of kaolinite. 
$X$-ray single-crystal experiments

Laue photograph. Laue photographs were taken of specimens A and $B$ with the $W$ radiation normal to the cleavage plane of the original biotite. The arrangement of diffuse spots shows nearly hexagonal symmetry for both specimens. This fact suggests that the alteration minerals in these specimens have an orientational relationship to the original biotite. The spots on the photograph for specimen A are more diffuse than those for specimen B. It follows, therefore, that the minerals in specimen $B$ exhibit a higher degree of orientation with respect to the original biotite.

Oscillation photograph. For specimen A, an oscillation photograph was taken around the $b$-(or pseudo $b$-) axis of kaolinite. The photograph obtained (Fig. 10) is a superposition of rings and diffuse spots. The rings can be indexed as reflections from gibbsite. The basal reflections are missing, and, on each ring, six intense portions arrange themselves hexagonally. These facts suggest that the basal plane of each gibbsite crystal is parallel to the cleavage plane of the original biotite, and that its $a$-and $b$-axes are randomly oriented in the cleavage plane, taking orientations more or less preferred. The diffuse spots are interpreted as follows: the basal plane (001) of the kaolinite is parallel to the cleavage plane of the original biotite, and the kaolinite crystals take either of the two orientations which are related to each other by a reflection across the plane (001) as shown in Fig. 11. Basal planes of the kaolinite crystals are not exactly parallel, but are arranged in a curly layer.

Weissenberg photograph. A normal-beam Weissenberg photograph was taken of specimen A rotated around the $b$-axis of kaolinite. All the reflections show marked streaking probably indicating a curly arrangement of the basal planes. Most of the spots correspond to the reciprocal lattice points of kaolinite in the two orientations stated above, and the spots which do not fit the kaolinite lattice can be attributed to the reflections from gibbsite randomly oriented as 


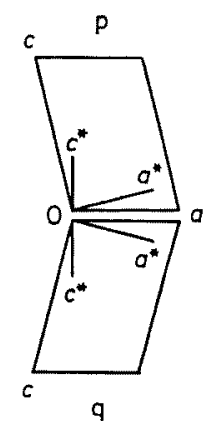

A

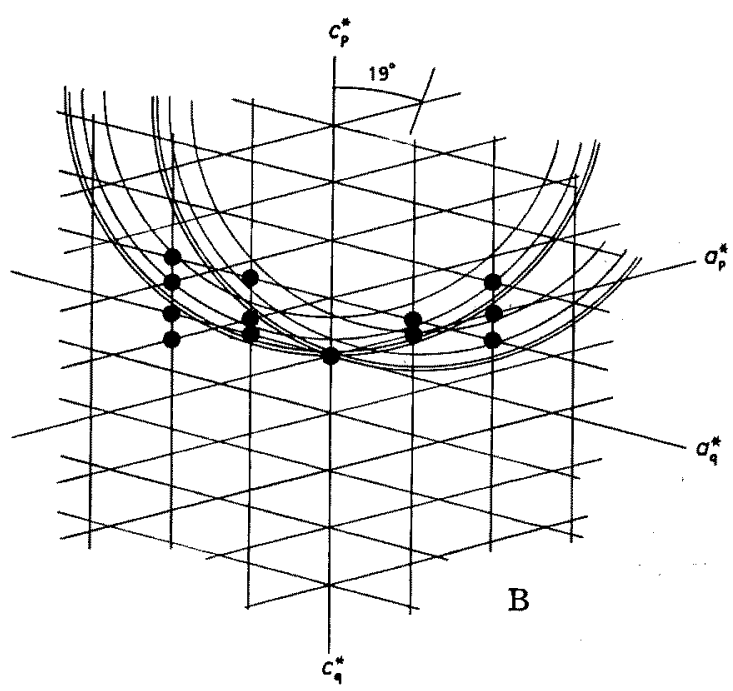

Fig. 11. A: Diagram showing the relation between two orientations assumed for kaolinite crystals. B: Reciprocal lattice representation of oscillation photograph of kaolinite in specimen A. 0, observed reflections.

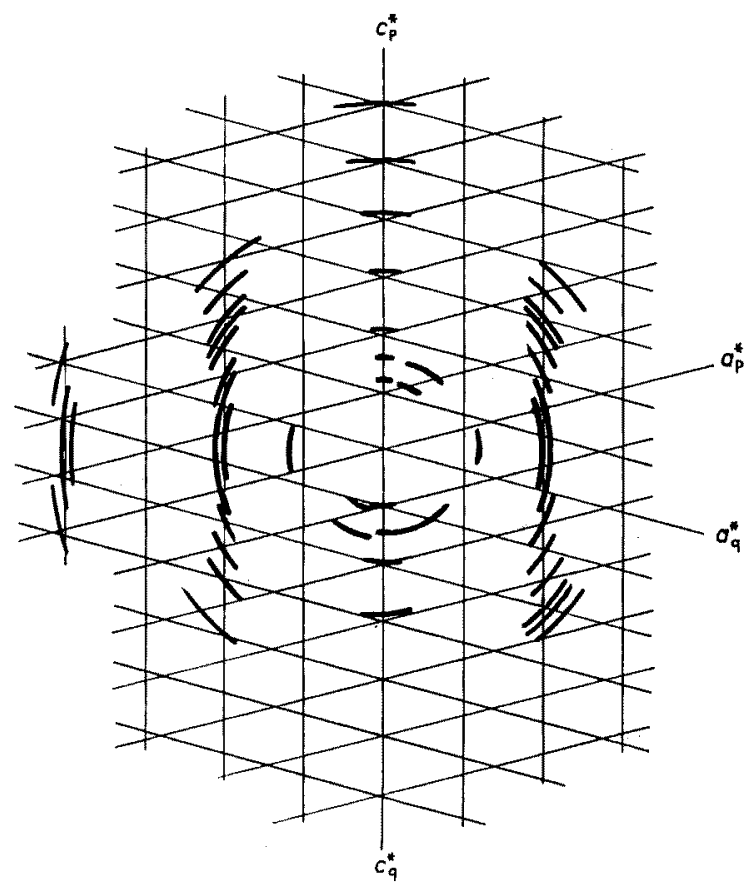

Fig. 12. Reciprocal lattice representation of normal-beam equatorial Weissenberg photograph of specimen A rotated around the $b$-axis of kaolinite. 
described above (Fig. 12).

\section{Discussion}

The alteration of biotite in the early stage of weathering is considered to proceed essentially through cation exchange reactions, that is, the replacement of interlayer potassium by other cations and by water, leaving the structure of the silicate layer intact. Jackson (1963) has described the way in which interlayer spaces of expanded 2:1 layer silicates in soil clays are aluminated. Trioctahedral Al-vermiculite in specimen B was probably formed by this mechanism together with partial exchange of the octahedral cations. This specimen has been elongated to about 1.5 times the height of the original biotite. This value can be explained by the replacement of $\mathrm{K}^{+}$by $\mathrm{Al}^{+++}$and $\mathrm{H}_{2} \mathrm{O}$.

On the other hand, if specimen A had been formed through cation exchange without accompanying removal or supply of oxygen, the height of the specimen would practically remain unchanged, because kaolinite and gibbsite have similar oxygen packing to the original biotite. Specimen A, however, is about three times as high as the original biotite in spite of the small pore space. In consequence, much material must have been introduced from the environment. The amounts of introduced materials were estimated on the assumption that specimen A had increased in volume three times of the original biotite, and that the chemical formula of the original biotite was $\mathrm{K}\left(\mathrm{Mg}_{1.5} \mathrm{Fe}_{1.5}\right)\left(\mathrm{AlSi}_{8}\right) \mathrm{O}_{10}(\mathrm{OH})_{2}$. The result is shown in Fig. 13, which indicates that a large part, about $90 \%$, of $\mathrm{Al}_{2} \mathrm{O}_{3}$ and $\mathrm{H}_{2} \mathrm{O}$ in specimen $\mathrm{A}$ and about $40 \%$ of $\mathrm{SiO}_{2}$ have been introduced.

Hydrobiotite has a structure and chemical composition similar to biotite. And the conoscopic examination revealed that the hydrobiotite has a well-defined orientation with respect to the original biotite. It is, therefore, reasonable to consider that the hydrobiotite has inherited the structure and material from the original biotite. 


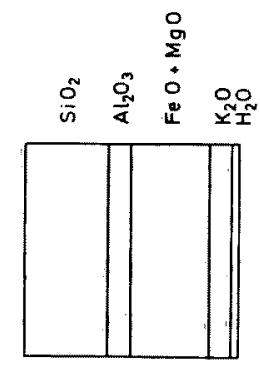

BIOTITE
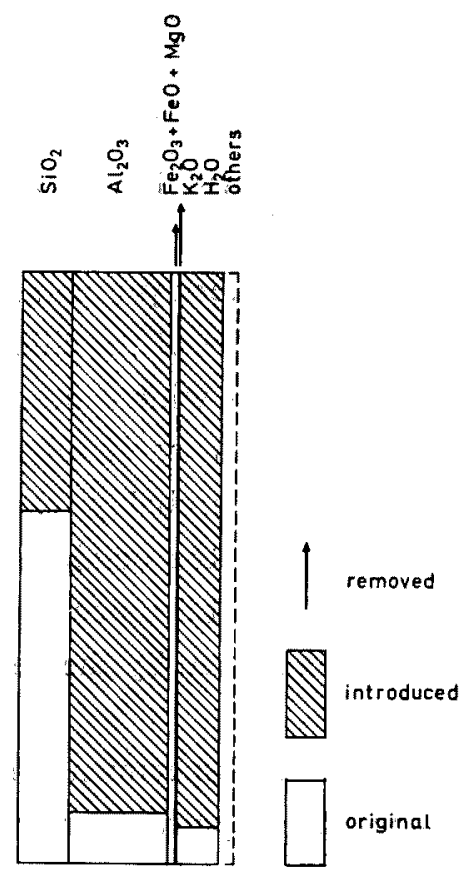

A

Fig. 13. A graphic representation showing amounts of introduced and removed materials on the formation of specimen A. The width of each column represents the weight percentage of each component. The difference in height between the original biotite (left) and specimen A (right) represents the increase in weight on weathering which corresponds to the elongation of crystals to three times.

After the allotment to hydrobiotite, the remaining $\mathrm{SiO}_{2}$ can fill $50 \%$ of the $\mathrm{SiO}_{2}$ content of kaolinite. On the other hand, $\mathrm{Al}_{2} \mathrm{O}_{3}$ which remains after the allotment to hydrobiotite can fill only $6 \%$ of the $\mathrm{Al}_{2} \mathrm{O}_{3}$ contents of kaolinite and gibbsite. Thus, it follows that, in order to form gibbsite, much more material need be supplied from the environment than the case of kaolinite formation. This reasoning is confirmed by the fact that the kaolinite was formed with a higher degree of orientation than the gibbsite with respect to the original biotite. 
The occurrence of gibbsite in the matrix of the gravel from which specimen A was collected (Fig. 3) suggests that a sufficient amount of aluminum was actually supplied to this horizon.

Disordered kaolinite is contained in specimen $\mathrm{A}$, while halloysite and metahalloysite are contained in the matrix of the gravel from which specimen A was collected. This difference in the kinds of kaolin mineral may be attributed to the origin: the former is an alteration product of biotite, while the latter two may have been formed by precipitation from solution without firm nucleus.

The writers wish to express their thanks to Dr. Mitsuoki Nakahira of the National Institute for Researches in Inorganic Materials, Dr. Akira Kawahara of the University of Tokyo, Dr. Kanenori Suwa of Nagoya University, and Dr. Kunihiko Miyakawa of Nagoya Institute of Technology for their helpful suggestions. The expenses were defrayed in part by a Grant-in-Aid for Fundamental Scientific Research, Ministry of Education.

\section{REFERENCES}

Bramão, L., Cady, J. G., Hendricks, S. B. \& Swerdlow, M. (1952). Soil Sci., 73, 273.

Cole, W.F. \& Hosking, J.S. (1957). The differential thermal investigation of clays, R.C. MAckenzle, editor, Mineralog. Soc., London, 248.

DeER, W.A., Howie, R.A. \& Zussman, J. (1962). Rock-forming minerals, Longmans, Green and Co., Ltd., London.

Fieldes, M. \& Swindale, L.D. (1954). New Zealand J. Sci. and Techn, 36B, 140.

IsовE, K. (1966). Chigaku Kenkyu, 17, 235.

Jackson, M. L., Hseung, Y., Corey, R. B., Evans, E. J. \& Vanden Heuvel,

R.C. (1952). Soil Sci. Soc. Amer. Proc., 16, 3.

Jackson, M. L. (1963). Clays and clay minerals, 11th Natl. Conf. Clays and Clay Minerals, 29.

Kato, Y. (1963). Advances in clay science, 4, Gihodo, Tokyo, 311.

Kato, Y. (1965). Soil Sci. and Plant Nutr. (Japan), 11, 30.

Kimura, I. \& TAKehara, H. (1965). Quatern. Research (Japan), 4, 69. MACKENZIE, R. C. (1957). The differential thermal investigation of clays, R. C. 
Mackenzie, editor, Mineralog. Soc., London, 299.

Rolfe, B. N. \& Jeffries, C. D. (1952). Science, 116, 599.

Tamura, T. (1958). J. Soil Sci., 9, 141.

WALKer, G.F. (1948). Clay Minerals Bull., 1, 5.

WALKER, G. F. (1949). Nature, 164, 577.

Wilson, M. J. (1966). Min. Mag., 35, 1080.

Manuscript received 5 June 1968 . 